\title{
SEPARATION OF CONTAMINANTS FROM DEINKING PROCESS WATER BY DISSOLVED AIR FLOTATION: EFFECT OF FLOCCULANT CHARGE DENSITY
} (Separation of contaminants from deinking process water by DAF)

\author{
Ruben Miranda, Angeles Blanco*, Elena de la Fuente, Carlos Negro \\ Dept. Chemical Engineering, Complutense University of Madrid, Madrid (Spain)
}

\begin{abstract}
The effect of charge density of 5 cationic polyacrylamides (C-PAMs) and 3 anionic polyacrylamides (A-PAMs) as single and dual treatments, with a coagulant, on the flocculation and removal of dissolved and colloidal material by dissolved air flotation (DAF) in papermaking has been studied. In single systems, the best results were achieved both with low and high charged C-PAMs (1.0 and 3.0-3.5 meq/g). In dual systems, high charged C-PAMs (3.0-3.5 meq/g) and A-PAMs (1.5 meq/g), were the most efficient. Results show that monitoring flocculation by a focused beam reflectance measurement (FBRM) allows papermakers to optimize the chemical dosages to maximize the separation efficiency of DAF units either with single or dual systems, which is not always possible with traditional methods as charge titration.
\end{abstract}

Keywords: dissolved air flotation, dissolved and colloidal material removal, flocculation, polyacrylamide, charge density, FBRM, papermaking

\footnotetext{
* To whom correspondence should be addressed. Address: Dpt. Chemical Engineering, Faculty of Chemical Sciences, Complutense University of Madrid, Avda. Complutense s/n, E-28040 Madrid, Spain. E-mail: ablanco@quim.ucm.es
} 


\section{INTRODUCTION}

Paper industry is one of the major industrial sectors in terms of water consumption during the manufacturing process, being the reduction of water use an issue of growing importance due to the stringent environmental legislation, the increase of water prices, the treatment costs, or simply due to the lack of water resources ${ }^{[1-2]}$. In fact, there are some products, mainly packaging paper/board, in which the runnability of the paper machine is not as sensitive as in printing paper manufacture, and zero liquid effluent has been already achieved, corresponding the fresh water consumed in the process only to the volume of water evaporated in the drying section (1.0-1.5 $\left.\mathrm{m}^{3 / \mathrm{t}}\right)^{[3-4]}$. In closed systems, the reuse of water increases the concentration of suspended, colloidal and dissolved substances. These substances can be organic, inorganic or biological in nature. While suspended solids are removed easily in the existing clarification systems, the dissolved and colloidal material (DCM) is almost completely recirculated into the process and, therefore, it accumulates and limits the closure of the water circuits. DCM negatively affects the production process (e.g. blockings, scaling, slime formation, breaks and stickies deposits) and the quality of the final product (by impairing its physical properties or by the presence of dirt and holes ${ }^{[5-7]}$. The main source of DCM is the recovered paper, although chemical additives used during the manufacturing process also contribute. DCM is mainly released during pulping, refining and bleaching ${ }^{[8-9]}$. Inorganic salts commonly found in papermaking are calcium, sulphates, chlorides, silicates, and also iron, manganese and copper; they are responsible for scaling phenomena, corrosion, odours, or the reduction of the efficiency of some additives ${ }^{[10]}$. Biological DCM, mainly bacteria, is the cause for slime formation, microbiologically-induced corrosion, generation of odours, degradation of some additives, etc. ${ }^{[11]}$. Organic compounds 
found in the dissolved and colloidal fraction of deinking process water are mainly adhesives, printing inks, coating binders, starches, deinking chemicals and wood extractives. They are responsible of secondary stickies deposits, which control is a key issue for papermakers ${ }^{[12-13]}$.

One of the most common internal treatments used in papermaking is dissolved air flotation (DAF), due to the fact that they can treat large water flows with a wide range of solids content, between $300 \mathrm{mg} / \mathrm{L}$ and $5000 \mathrm{mg} / \mathrm{L}$. For example, in recycled newsprint mills there are up to five DAF units $\left(1^{\text {st }}\right.$ loop, $2^{\text {nd }}$ loop, paper machine loop, sludge treatment and effluent treatment). In principle, DAF removes efficiently $80-98 \%$ of suspended solids, e.g. fibres, fines and fillers as well as a wide variety of contaminants such as ink particles and lypophilic extractives. Besides, with suitable chemicals, also finely dispersed and colloidal organic particles (>0.1-0.2 $\mu \mathrm{m})$, can be agglomerated and removed ${ }^{[14-17]}$. Best reductions of organic DCM obtained by microflotation, measured as COD, are in the range of $10-30 \%$, because COD load consists mainly of particles smaller than $0.2 \mu \mathrm{m}^{[14,18]}$. It is estimated that $85 \%$ of the TOC measured in the DCM fraction corresponds to dissolved substances and a $15 \%$ to colloidal substances ${ }^{[19]}$. Removal of colloidal substances, measured in terms of cationic demand is a little bit higher, in the range of $10-40 \%{ }^{[20]}$. Inorganic and biological DCM is not much affected by DAF, being necessary other water treatment technologies if these compounds are limiting a further closure of the water circuits.

A variety of chemical additives are used in DAF systems, usually supported by tailor-made chemicals $^{[21]}$. In general, there are three main flocculation strategies: a) single cationic flocculant: a low to medium cationic charge, very high molecular weight polymer, usually a CPAM. This approach is attractive because of its simplicity and low cost; b) dual systems: cationic 
coagulant and anionic flocculant. A high cationic charge, low molecular weight coagulant, most of the times a poly(diallyldimethylammonium chloride) (poly-DADMAC) or a polyamine, used in conjunction with a high molecular weight anionic flocculant (e.g. A-PAM). The coagulant is first added, to neutralise the anionic charge and coagulate the sample. Then, a small amount of a long chain anionic flocculant is added to form the main flocs; c) dual systems: cationic coagulant and cationic flocculant. Most of the times, the cationic flocculant is used as a single component but when its efficiency is low, a cationic coagulant is added to neutralize the anionic trash and increase the flocculation efficiency of the flocculant.

Flocculation is a complex phenomena in which various processes occur simultaneously: adsorption of polymer molecules on the particles surface; rearrangement (or re-conformation) of adsorbed polymeric chains; collisions between particles forming aggregates (flocs); and break-up of flocs ${ }^{[22]}$. The importance of each process depends on various factors as: i) the flocculant characteristics: structure, molecular weight, charge density and concentration; ii) the characteristics of the suspended particles: size and charge density; iii) the characteristics of the suspending medium: $\mathrm{pH}$, conductivity and ionic charge; and, iv) the contact time and turbulence intensity, among others ${ }^{[23-25]}$.

The interaction of polymers with DCM and their effect on flocculation is determined by nonspecific electrostatic interactions. Electrostatically stabilized colloids with similar charges can be aggregated by increasing the ionic strength or by adding a polyelectrolyte into the system and, consequently, removed by $\mathrm{DAF}^{[26-27]}$. One of the afore mentioned parameters that most strongly affects flocculation is the charge density of the polyelectrolyte, because it determines its 
conformation when it is adsorbed on the particle surface, and, therefore, the predominant flocculation mechanism ${ }^{[22-23,28]}$. In general, if molecular weight is high and charge density is low, the polymer adsorbs on the particle surface in such a way that tails and loops are extended far beyond the surface interacting with other particles - in this case the flocculation process is dominated by bridging. When the charge density is high, the bridging capability is reduced because the polymer chains adopt a flat conformation on the particle surface, which results in the formation of cationic patches that attract the polymer free surfaces of other particles. In this case, the adsorption rate becomes lower and the conformation rate becomes faster as the cationic charge of the polymer increases ${ }^{[22,29-31]}$.

Bridging is the dominating mechanism in the flocculation of DCM with PAMs ${ }^{[29,32-33]}$ and, in general, flocculation efficiency improves when charge density increases ${ }^{[34]}$. However, there is an optimal charge density depending on the colloidal nature of the system ${ }^{[25,35-36]}$.

Therefore, the objectives of the present study are: first, to examine the interactions between cationic and anionic PAMs of various charge densities, used in single and dual systems, and the DCM from deinking process water and to determine its efficiency to remove DCM by DAF; and second, to optimize the DAF efficiency by optimization of chemical dosages based on the online monitorization of flocculation by FBRM. 


\section{MATERIALS AND METHODS}

Materials. Water samples were taken from the inlet of a DAF unit in loop 2 (pulp preparation stages) of a paper mill producing newsprint from 100\% recovered paper. All trials and analyses were carried out within 48 hours after the sampling to avoid the possible degradation of the waters.

Several combinations of single and dual flocculation systems have been studied. Flocculants studied are five C-PAMs, with the same molecular weight but different charge densities, from 1.0 to $3.5 \mathrm{meq} / \mathrm{g}$, and three A-PAMs, with the same molecular weight and charge densities ranging from 0.75 to $1.5 \mathrm{meq} / \mathrm{g}$. The coagulant used (SC) is a high molecular weight polyamine type based on blends of cationic copolymers with different charges. Chemicals were supplied by SERTEC-20 (Spain). Polymer properties, as reported by the supplier, are listed in Table 1.

Doses of the products used at lab-scale were given by the supplier based on previous tests. Flocculant dosage was fixed to $20 \mathrm{mg} / \mathrm{L}$; this dosage is higher than at industrial scale due to the lower hydrodynamic efficiency of the lab DAF cell compared to the industrial ones. Coagulant dosage was fixed to $500 \mathrm{mg} / \mathrm{L}$ to obtain a reduction of approximately a $75 \%$ of the cationic demand of the fed waters; this dosage is high enough to remove most of the DCM without achieving the isoelectric point and without blocking the particle sites necessary for the further flocculation by bridging ${ }^{[19,31,37-38]}$. 
Methodology for DAF tests. Experiments were carried out in a lab-scale DAF unit (Flottatest FTH3), supplied by Orchidis Laboratoire. Both coagulant and flocculants were added from 1.0 wt\% stock solutions to $1 \mathrm{~L}$ of sample. A blank was carried out without adding any chemical, for considering the dilution of the samples as consequence of the addition of air saturated water during flotation (200 mL); this reference sample is named REF. Experiments were carried out at room temperature $\left(20-25^{\circ} \mathrm{C}\right)$.

Efficiency of the different treatments was evaluated by turbidity, cationic demand and chemical oxygen demand (COD) of the feed and the clarified waters, as shown in Figure 1. Turbidity was measured with a Hanna LP-2100 turbidimeter. Cationic demand was measured with a particle charge detector PCD 03 (Mütek GmbH) and an automatic titrator Compact I (Crison Instruments SA), using poly-DADMAC $0.001 \mathrm{~N}$ as titrant. COD was measured by Merck Spectroquant ${ }^{\circledR}$ COD 300-3500 method, using an Aquamate Vis spectrophotometer (Thermo Scientific Inc.). pH and conductivity of the raw waters were also analyzed, using a GLP-22 pH-meter and a GLP-32 conductivity meter (both supplied by Crison Instruments, S.A.).

Methodology for flocculation tests. Flocculation was monitored using a FBRM device, model M500LF, supplied by Mettler Toledo. This device generates a highly focused laser beam that describes circles at a fixed high speed. When particles intercept its path, the light is reflected and driven to the detector. The time duration of the backscattered light pulse allows calculating the particle chord length, in the range $1-1000 \mu \mathrm{m}^{[30,32]}$. From these data, total counts, counts in specific size intervals, mean chord size, and other statistical parameters can be easily calculated. The evolution of these statistics reflects the evolution of the flocculation process of suspended 
particles and DCM in real time ${ }^{[19,28,39-41]}$. This system is able to predict flocculation behaviour without the limitations of traditional methods as charge titration which are not valid when bridging or patching mechanisms dominate the system ${ }^{[22]}$. Recently, FBRM has been used for the chemical optimization of DAF units treating thermomechanical pulp waters ${ }^{[27,33]}$.

In a typical trial, the probe is submerged into $150 \mathrm{~mL}$ of sample stirred at $400 \mathrm{rpm}$. After one minute of stirring, the coagulant is added. Then, the system is allowed to evolve during $60 \mathrm{~s}$ before adding the flocculant. The evolution of the system is monitored during 2-3 minutes after flocculant addition. The same procedure is used for single systems, where only the flocculant is added.

\section{RESULTS AND DISCUSSION}

The characterization of the waters from the inlet of the industrial DAF unit is shown in Table 2. Figure 2 shows the chord size distribution of the fed waters, measured by the FBRM technique. Mean chord size is $2.7 \mu \mathrm{m}$. The shape of the chord size distribution also indicates that there is a considerable proportion of DCM $(<1 \mu \mathrm{m})$ in the waters.

The mill has experienced problems in the removal of contaminants with this unit due to the presence of a very stable colloidal system, as consequence of the low but highly concentrated surface charge of the colloids. These colloids are mainly organics, released from the recovered paper in the bleaching stage with hydrogen peroxide and sodium silicate. Bleaching with hydrogen peroxide produces soluble and highly anionic compounds due to the oxidant effect of 
the peroxides, leading to COD, cationic demand and colloid concentration increase ${ }^{[42-43]}$. On the other side, sodium silicate, commonly added in the bleaching stage for reducing the hydrogen peroxide decomposition with metal ions, enhances the release of more cationic demand from the recovered paper at the same time that colloid size is decreased ${ }^{[43]}$, being very detrimental for the clarification of waters. For example, if the amount of silicates is high (above 1\%), the clarification is very difficult, e.g. waters with a $2 \%$ concentration of silicates require a tripled dose of coagulant to obtain the same water quality, compared to waters with a $1 \%$ silicates concentration $^{[20]}$. To achieve the destabilization of the colloidal system two conditions are necessary: a good adsorption of the coagulant and polymers on the particles surface, difficult due to the rather low surface charge of the particles in this system; and a good agglomeration of the particles, after the re-conformation of the adsorbed polymeric chains. With the traditional methods of testing, mainly charged related measurements, it is not easy to know if the process is leaded by one force or another, but using the FBRM, additional information can be obtained.

Single systems. The effect of adding only flocculant was studied to determine the suitability of these systems for cleaning the feed waters, and for a subsequent comparison with dual systems. If the contaminants are mainly suspended solids, single systems are usually enough for obtaining good clarification of waters ${ }^{[44-45]}$, but dual systems are necessary if the removal of finely dispersed and colloidal particles is required ${ }^{[15-16]}$. Figure 3 summarizes the results of turbidity, cationic demand and COD of the clarified waters obtained in the DAF tests. As it was expected, anionic flocculants are not able to interact with the contaminants present in the waters, because of their anionic charge. Cationic flocculants reduced the turbidity by $20-50 \%$, being the flocculant with lowest charge (C1), the most efficient. COD reductions were very low $(<5 \%)$, 
except for the flocculant of the highest charge (C5), which obtained a $10 \%$ reduction. Similar reductions of cationic demand were achieved with the different C-PAMs, ranging from 13 to 23\%; C1 and C5 were the most efficient ones (> 20\% reduction).

Results show that there is not a clear relationship between the charge density of the flocculant and its efficiency in DAF, although previous works, focused on the destabilization of DCM in TMP process waters, have shown that high charged C-PAM achieves better removal of contaminants than low-charged C-PAMs (mainly related to wood extractives contents) ${ }^{[27,36,47]}$. In principle, higher charged C-PAMs are usually preferred to low charged ones, although there is a limit, because a very high charge density may be detrimental, causing a slight reduction in the adsorption of contaminants ${ }^{[47]}$. However, in this study, the most efficient C-PAMs are both the lowest charged one (C1) and the highest charged one (C5). Only a few authors have reported that a C-PAM with low charge density was more effective in removing DCM than high charged CPAMs. M. Nurmi et al. ${ }^{[24]}$ tested two C-PAMs with the same molecular weight $\left(7 \cdot 10^{6} \mathrm{~g} / \mathrm{mol}\right)$ and different charge densities: 1.0 and $1.5 \mathrm{meq} / \mathrm{g}$, and obtained that C-PAM with the lowest charge density was more effective. Something similar was observed by Wagberg et al. ${ }^{[48]}$, who found that a high charge density C-PAM (1.89 meq/g) was more efficient at lower levels of polymer addition, but C-PAMs with lower charge densities (0.36 and $0.62 \mathrm{meq} / \mathrm{g}$ ) had higher flocculation ability over a large range of polymer dose, indicating that low charged C-PAMs were the most efficient flocculants at high dosages, as those used in this study because of the high stability of the colloidal system. 
The possible explanation of a higher efficiency of the low charged C-PAMs can be related to the bridging mechanism, recognized to be the dominating mechanism in the flocculation of deinked and TMP waters with C-PAM ${ }^{[32-33]}$.

Figure 4 shows the proposed scheme of the flocculation mechanism induced by C1, case A, and by one of the higher charged C-PAMs, case B. Anionic charge of colloids in this system is low but it is concentrated in some zones on the particle surface. Attractive forces (electrostatic ones) between $\mathrm{C} 1$ and particle surface are weak because of the low charge of polymer. Therefore, adsorbed chains keep a highly extended conformation. Because of this, and due to the low polymer charge, the number of chains that can interact with each particle is higher than in the case $\mathrm{B}^{[24,48]}$. Therefore, more bridges can exist between each particle and the adjacent ones, forming large flocs that aggregate slowly to form very large flocs. Floc density is low because bridges among particles in these flocs are long; therefore, flocs are easy to remove by flotation. In case B, electrostatic forces between particle and chain are stronger; therefore: i) conformation of adsorbed chains is less extended; ii) less number of chains can interact with each particle because the repulsion between the charged groups, consequently, lower number of bridges can be form from each particle with the others and the flocs are smaller ${ }^{[49]}$; iii) bridges are shorter than in the case A, flocs would be more compact and denser, and thus, more difficult to float. However, the higher neutralization ability of the highly charged C-PAMs increases the efficiency in anionic colloids neutralisation, when C4 and C5 are used at the same dosage than the other C$\mathrm{PAMs}^{[36]}$. In the case of $\mathrm{C} 5$, the charge density could be high enough to induce the evolution of the bridging flocculation mechanism towards patching ${ }^{[22]}$. 
Figure 5 shows the chord size distribution obtained by the FBRM $10 \mathrm{~s}$ after the addition of the different flocculants, when the degree of flocculation is maximum. In general, flotation is promoted by large flocs, although, in some cases, a low mean chord size with a higher number of counts can mean that DCM has been destabilised and aggregated forming small flocs that can be also removed subsequently by flotation ${ }^{[27]}$. Chord size distribution obtained with A-PAMs is similar to that of raw waters (RW) because they did not interact with the detrimental material. Addition of C-PAMs increases the area of chord size distribution and moves it towards larger chord sizes, indicating the flocculation of colloids smaller than $1 \mu \mathrm{m}$. The area of the chord size distribution increases with polymer charge density, being C5 the one that forms more and larger flocs from colloids smaller than $1 \mu \mathrm{m}$ in $10 \mathrm{~s}$. Flocs aggregate in a second stage decreasing strongly the number of chords between 1 and $10 \mu \mathrm{m}$ when C1 was used, as shown in Figure 6, but this second stage takes a longer time than $10 \mathrm{~s}$. In this case, a sharp decrease in the number of counts was also observed in all the higher chord sizes intervals, indicating the formation of flocs larger than $1000 \mu \mathrm{m}$, easily removed in the DAF unit. Consequently, the chord size distribution shown in Figure 5 does not represent exactly the moment in which the flocculation of C1 is maximum because of its slower kinetics compared to the other flocculants. As consequence, nucleation and growing of flocs can be distinguished ${ }^{[22]}$.

Total number of counts increases with the DCM destabilization because most of the colloidal material is initially below the detection limit and reaches a final value that could be related to the global flotation efficiency. In our study, a high increase in the total number of counts from around 500 \#//s to around 7000 \#/s for all C-PAMs was observed, except for C5 (11000 \#/s), and no increase in the number of counts was observed for A-PAMs. After the initial increase in the 
number of particles, these can increase, decrease or remain stable. The final value of number of counts is in the following order: C5 $>$ C4 $>$ C3 $>$ C2 $>$ C1, similar to the efficiency obtained in the DAF tests except for C1. The same results were observed analyzing the mean chord size. Behaviour of C1 is clearly different compared to the other C-PAMs.

Table 3 shows the relationship between the cationic demand of the clarified waters, different statistics from FBRM and the DAF efficiency in removing turbidity and COD. Cationic demand and FBRM statistics predict the efficiency in DAF processes, especially if C1 is not considered in the fits, due to its different flocculation behaviour. In this case, the correlations are as high as $\mathrm{R}^{2}=0.946$ and $\mathrm{R}^{2}=0.868$ for turbidity and COD, respectively, using for example the number of counts per second with sizes in the interval 10-100 $\mu \mathrm{m}$ (Figure 7).

Dual systems. Figure 8 summarizes the efficiency of dual systems in DAF tests; results obtained for the addition of only coagulant are also included. Coagulant combined with A-PAMs reduced $70-90 \%$ of turbidity, $15-20 \%$ of COD and $70-75 \%$ of cationic demand. If C-PAMs are used, the reductions vary between $1 \%$ and $90 \%$ of turbidity, $10-20 \%$ of COD and $90-95 \%$ of cationic demand. Results obtained with the best A-PAM (A3) and the best C-PAMs (C4 and C5) are similar, except for the cationic demand, because of the contribution of the charge of the polymers to the total charge measured by colloidal titration. The coagulant caused very little aggregation by itself (only a 7\% reduction of turbidity and 6\% of COD), but induced an important increase in the aggregation achieved by a subsequent PAM addition due to the neutralization of the anionic charge, that facilitates the destabilisation of DCM, and increases the amount of free C-PAM available to flocculate the aggregates ${ }^{[19,42]}$. However, there is a limit in the dosage of coagulant, 
if too much coagulant is added, particles start to repel each other due to steric and electrostatic stabilization. This occurs near the isoelectric point of the waters. In our study, the dosage of coagulant was fixed to obtain a reduction of the cationic demand of around $75 \%$ of the fed waters to avoid the total neutralization of the waters, especially considering that C-PAMs are used in conjunction with the coagulant, but enough for avoiding the detrimental effects of DCM, because some of these effects are removed only after the neutralization of most of the DCM charge demand ${ }^{[19]}$.

Results show a clear relationship between the turbidity removal and the charge density of the flocculants when coagulant is added first. High charged A-PAM (A3) is more efficient than low charged A-PAMs (A1 and A2) because of the high interaction with the coagulant adsorbed on colloids. In the case of C-PAMs, the optimum charge density is 3.0-3.5 meq/g (C4 and C5). C4 achieved the highest reduction of turbidity (90\%), a 19\% reduction of COD and a 95\% of cationic demand (residual cationic demand is only $30 \mu \mathrm{eq} / \mathrm{L}$, near to the total charge neutralization). In presence of coagulant, electrostatic forces among C-PAM and particles are lower because of the lower remaining charge of particle surface. Therefore, adsorption of C1 is too weak to form useful flocs while flocculants with higher charge density can adsorb with an extended conformation and form larger flocs. Some authors have reported good removal efficiencies of dual systems for wood extractives too. They have observed that the point of charge reversal and the point of optimal flocculation differed considerably from each other in bridging flocculation, as occurred in presence of single systems, but when dual systems were used, the maximum DCM removal was obtained for a coagulant dosage close to the isolectrical point ${ }^{[24,46,50-51]}$. 
Figure 9 shows the chord size distributions of the suspension $10 \mathrm{~s}$ after adding the flocculant, when it is part of the dual system. Best treatments (C4, C5 and A3) caused a very broad, almost flat, chord size distribution, with a high number of particles with chord sizes larger than $100 \mu \mathrm{m}$. This kind of distribution curves is typically obtained when flocs larger than $1000 \mu \mathrm{m}$ are formed because they are out of the measurement interval of the FBRM probe. These types of chord size distribution cannot be characterized by the mean chord size. If the rest of the chemical treatments are considered, it is observed that the efficiency of DAF systems is related to the maximum of the mean chord size distribution.

The analysis of the evolution of the number of counts in the interval from 1 to $10 \mu \mathrm{m}$ (Figure 10) provides further information about the efficiency of the different treatments. The addition of the coagulant initially caused a high increase of small particles (1 to $10 \mu \mathrm{m}$ ), because it induces the flocculation of DCM $(<1 \mu \mathrm{m})$ to form microflocs, which evolve towards an equilibrium, decreasing the number of counts in that size interval. Flocculant induces the aggregation of microflocs to form larger flocs, as it is reflected by the decrease in the number of counts in this interval. The sharper this decrease, the more efficient is the flocculant in the aggregation of microflocs to form large flocs, which could be easily removed by DAF. The two flocculants with the lowest efficiencies, (C1 and C2), can be easily distinguished from the rest of flocculants because neither of them is able to induce the aggregation of microflocs and an increase in the number of particles 1-10 $\mu \mathrm{m}$ is observed due to the formation of, therefore, more microflocs by DCM destabilisation after the addition of the flocculant. 
Total number of counts can be also analyzed to obtain further information about the process (Figure 11). The addition of the coagulant induced a very sharp increase in the total number of counts from around $500 \# / s$ to $9500-10000 \# / s$ (more than a $70 \%$ of these increase is in the size range 1-31.6 $\mu \mathrm{m})$. This value remained almost constant until the addition of the flocculant. Then, more efficient products reduced sharply the number of counts to around 1000 \#/s (C4 and C5), and to 2000 \#/s for A2 and A3. Products with an intermediate efficiency, such as A1 and C3, reduced the number of counts to around 3000-4000 \#/s and increase the number of counts larger than $100 \mu \mathrm{m}$. C1 and C2, on the opposite, increased the number of counts over $11000 \mathrm{\#} / \mathrm{s}$ and all of them were smaller than $100 \mu \mathrm{m}$. This corroborates that these flocculants are not able to form larger flocs from the destabilised DCM and, consequently, their efficiency for removing contaminants by DAF is low.

The analysis of the mean chord size evolution corroborates these observations (Figure 12). The addition of the coagulant yielded little increase of this statistic (from $10 \mu \mathrm{m}$ to $25 \mu \mathrm{m}$ ), and then, it remained constant, as already observed by A.J. Dunham et al. ${ }^{[19]}$. After the flocculant addition, most efficient products showed a sharp increase of the mean chord size (up to $110 \mu \mathrm{m}$ ). Intermediate efficient products such as A1 and C3 produced a progressive increase in the mean chord size, although final value was lower. In the case of less efficient products (C1 and C2) the mean chord size showed only a small increase after flocculant addition.

Contrarily to the observations made with single systems, the efficiency of the dual systems cannot be successfully correlated with the final cationic demand of the waters. In principle, if neutralization is the main flocculation mechanism, the optimal removal efficiency should be at 
the isoelectric point. Therefore, this fact indicates that, although coagulant acts by neutralization mechanism, the flocculants do not. For this reason, relatively low differences in cationic demand, e.g. $90 \mu \mathrm{eq} / \mathrm{L}(\mathrm{C} 1)$ and $60 \mu \mathrm{eq} / \mathrm{L}(\mathrm{C} 5)$, implied high differences in the removal of contaminants: $1 \%$ and $85 \%$ turbidity removal, respectively.

Therefore, other measurements are necessary to predict and control the efficiency of the process. In this sense, FBRM is a valuable tool independently if single or dual systems are tested. For example, good correlations have been observed for the number of counts with sizes in the interval (10-100 $\mu \mathrm{m})$ (Figure 13), the total number of counts, and the mean chord size (Table 4).

\section{CONCLUSIONS}

Dual systems are necessary for the clarification of deinking process waters with DAF because of the high stability of this colloidal system. A maximum reduction of $50 \%$ of turbidity and $10 \%$ of COD is achieved by C-PAMs alone. Dual systems, either based on C-PAMs or A-PAMs, achieved reductions of $90 \%$ in turbidity and $20 \%$ in COD.

Although it is generally believed that C-PAMs with higher charge density are more efficient when they are used as single systems in DAF units, it has been demonstrated that low charged CPAMs can be efficient in DAF treatments for deinking process waters because of their capacity to form more and larger bridges between particles, giving larger and less dense flocs. However, recharging of particles increases with charge density of the flocculant and, therefore, the DCM destabilisation, which explains the high efficiency of the highest charged C-PAM tested. 
The advantages of low charged flocculants become a drawback when coagulant is added before, in dual systems. Then, efficiency increases with charge density of the flocculant, as it was expected.

For single systems, although the dominating flocculation mechanism is bridging, the flocculation efficiency can be predicted based on charge measurements as cationic demand or zeta potential., In dual systems, however these measurements do not correlate with the efficiency of DAF, although coagulation takes place by charge neutralization.

Monitorisation of chemical flocculation by FBRM gives us valuable information to predict and control the efficiency of different chemical treatments in DAF for both single and dual systems. Number of counts between 10 and $100 \mu \mathrm{m}$ per second represents a useful parameter to correlate flocculation monitoring and the efficiency of DAF systems. The square correlation index between this parameter and turbidity and COD is 0.891 and 0.840 , respectively, for dual systems. In the case of single systems, if C1 is not considered due to its different flocculation behaviour, square correlation index is 0.946 for turbidity and 0.868 for COD.

\section{ACKNOWLEDGEMENTS}

The authors wish to acknowledge the support of PROLIPAPEL-CM project (S-505/AMB/0100) by the Community of Madrid (Spain) and SHAKER project (COOP-CT-032352) by the European Union. Holmen Paper Madrid and SERTEC-20, especially Jordi Sanchez, are also deeply acknowledged for their collaboration. 


\section{LITERATURE CITED}

1. Thompson, G.; Swain, J.; Kay, M.; Forster, C.F. The treatment of pulp and paper mill effluent: a review. Biores. Technol. 2001, 77 (3), 275.

2. Blanco, A.; Negro, C.; Monte, C.; Fuente, E.; Tijero, J. The challenges of sustainable papermaking. Env. Sci. Technol. 2004, 38 (21), 414.

3. Gubelt, G.; Lumpe, C.; Verstraeten, E.; Joore, L. The validation of two novel separation technologies in a ZLE concept via in-mill research at recovered paper mill Niederauer Muhle (Germany). Wochenbl. Papierfabr. 2001, 129 (5), 2892.

4. Oinonen, H. In search of zero emissions: the latest European paper mills have achieved some remarkable advances in effluent water treatment. Pulp Pap. Int. 2003, 45 (5), 24.

5. Bourgogne, G.; Laine, J.E. A review of the effects of reduced water consumption on the wet end of the paper machine and the quality of water. Pap. Puu-Pap. Timb. 2001, 83 (3), 190.

6. Curley, J.; Jones, B.; Wiseman, N.; Xiao, H. Reducing the reliance of fresh water. Pap. Technol. 1999, 40 (3), 49.

7. Blanco, A.; Negro, C.; Monte, C.; Fuente, H.; Tijero, J. Overview of two major deposit problems in recycling: slime and stickies. Part II: stickies problems in recycling. Prog. Pap. Recycl. 2002, 11 (2), 26.

8. Basta, A.H.; Zhan, H.; He, B.; Wang, X.; Zao, G.; Chen, J. Cleaning efficiency of process water in newsprint mill. Prog. Pap. Recycl. 2004, 13 (3), 13.

9. Brun, J.; Delagoutte, T.; Carre, B. Origins and effects of dissolved and colloidal materials. Prog. Pap. Recycl. 2007, 17 (1), 12.

10. Berard, P. Filling in the holes after closing the loop. Pulp Pap. Int. 2000, 42 (4), 45. 
11. Blanco, A.; Negro, C.; Monte, C.; Tijero, J. Overview of two major deposit problems in recycling: slime and stickies. Part I: slime problems in recycling. Prog. Pap. Recycl. 2002, 11 (2), 14.

12. Sarja, T. Measurement, nature and removal of stickies in deinked pulp. Thesis dissertation. 2007. University of Oulu (Finland).

13. Miranda, R.; Balea, A.; Sanchez de la Blanca, E.; Carrillo, I.; Blanco, A. Identification of recalcitrant stickies and their sources in newsprint production. Accepted in Ind. Eng. Chem. Res. 2008.

14. Roring, A.; Wackerberg, E. Characterization of deinking white water - Influence on flotation and bleaching efficiency. Pulp Pap. Can. 1997, 98 (5), 17.

15. Meixner, H.; Auhorn, W.J., Gercke, M. Tailor-made cationic polymers for fixing detrimental substances of primary and secondary origin. Papier 1998, 52 (10A), 36.

16. Ben, Y.; Dorris, G.; Hill, G.; Allen, J. Contaminant removal from deinking process water. Part I: Mill benchmarking. Pulp Pap. Can. 2003, 104 (1), 42.

17. Ben, Y.; Dorris, G.M.; Page, N. Characterization of dissolved air flotation rejects. Pulp Pap. Can. 2004, 105 (11), 28.

18. Putz, H.K. Stickies in recycled fiber pulp. In: Göttsching, L. and Pakarinen, H. (eds). Papermaking Science and Technology, Book 7, Recycled Fiber and Deinking; Fapet Oy: Jyväskylä (Finland), 2000, 441-498.

19. Dunham, A.J.; Tubergen, K.R.; Govoni, S.T.; Alfano, J.C. The effects of dissolved and colloidal substances on flocculation of mechanical pulps. J. Pulp Pap. Sci. 2000, 26 (3), 95. 
20. Brun, J.; Carre, B. Potential of dissolved air flotation to remove colloidal and dissolved materials in order to reduce deposits. $1^{\text {st }}$ CTP-PTS Packaging paper and board recycling, Grenoble, France, 29 Nov.-1. Dec. 1999. CTP (Grenoble, France), 1999, vol. 2, 21 pages.

21. Pelzer, R.; Kenzel, U. Polyacrylamides (PAM) for process water treatment in the production of mechanical printing papers. Wochenbl. Papierfabr. 2006, 134 (22), 1320.

22. Rasteiro, M.G.; Garcia, F.A.P.; Ferreira, P.; Blanco, A.; Negro, C.; Antunes, E. The use of LDS as a tool to evaluate flocculation mechanisms, Chem. Eng. Process. 2007, doi: 10.1016/j.cep.2007.04.009.

23. Bremmell, K.E.; Jameson, G.J.; Biggs, S. Kinetic polyelectrolyte adsorption at the solid/liquid interface interaction forces and stability. Colloid Surf. 1998, 139 (2), 199.

24. Nurmi, M.; Byskata, J.; Eklund, D. Factors influencing flocculation of dissolved and colloidal substances in thermomechanical pulp water. J. Pulp Pap. Sci. 2004, 30 (2), 41.

25. Nasser, M.S.; James, A.E. The effect of polyacrylamide charge density and molecular weight on the flocculation and sedimentation behaviour of kaolinite suspensions. Sep. Purif. Technol. 2006, 52 (2), 241.

26. Negro, C.; Blanco, A.; Saarimaa, V.; Tijero, J. Optimization of pitch removal by dissolved air flotation in a Ecualyptus kraft mill. Sep. Sci. Technol. 2005, 40 (5), 1129.

27. Saarimaa, V.; Sundberg, A.; Holmbom, B.H.; Blanco, A.; Negro, C.; Fuente, E. Purification of peroxide-bleached TMP water by dissolved air flotation. Tappi J. 2006, 5 (5), 15.

28. Blanco, A.; Negro, C.; Fuente, E.; Tijero, J. Effect of shearing forces and flocculant overdose on filler flocculation mechanisms and floc properties. Ind. Eng. Chem. Res. 2005, 44 (24), 9105. 29. Biggs, S.; Habgood, M.; Jameson, G.J., Yan, Y.D. Aggregate structures formed via a bridging flocculation mechanism, Chem. Eng. J. 2000, 80 (1-3), 13. 
30. Blanco, A.; Fuente, E.; Negro, C.; Tijero, J. Flocculation monitoring: focused beam reflectance measurement as a measurement tool. Can. J. Chem. Eng. 2002, 80 (4), 734.

31. Swerin, A.; Swerin, A.; Glad-Nordmark, G.; Odberg, L. Adsorption and flocculation in suspensions by two cationic polymers-simultaneous and sequential addition. J. Pulp Pap. Sci. 1997, 23 (8), J389.

32. Blanco, A.; de la Fuente, E.; Negro, C.; Monte, M.C.; Tijero, J. Focused beam reflectance measurement as a tool to measure flocculation. Tappi J. 2002, 1 (10), 14.

33. Saarimaa, V.; Sundberg, A.; Holmbom, B.; Blanco, A.; Fuente, E.; Negro, C. Monitoring of dissolved air flotation by focused beam reflectance measurement. Ind. Eng. Chem. Res. 2006, 45 (21), 7256.

34. Abraham, T.; Christendat, D.; Xu, Z.; Masliyah, J.; Gohy, J.F.; Jerome, R. Role of polyelectrolyte charge density in tuning colloidal forces. AIChE J. 2004, 50 (10), 2613.

35. Neimo, L., in Papermaking Chemistry, vol. 4 of Papermaking Science and Technology; Fapet Oy: Helsinki, Finland, 1999.

36. Nurmi, M.; Wallin, S.; Eklund, D. The effect of molar mass and charge density of cationic polycrylamide on the flocculation of dissolved and colloidal substances in thermomechanical pulp water. J. Pulp Pap. Sci. 2006, 32 (1), 43.

37. Swerin, A.; Odberg, L.; Wagberg, L. An extended model for the estimation of flocculation efficiency factors in multicomponent flocculant systems. Colloids Surf. A: Physicochem. Eng. Aspects 1996, 113 (1-2), 25.

38. Wagberg, L.; Eriksson, J. New equipment for detection of polymer induced flocculation of cellulosic fibres by using image analysis - application to microparticle systems. Chem. Eng. J. 2000, 80 (1-3), 51. 
39. Negro, C.; Fuente, E.; Blanco, A.; Tijero, J. Flocculation mechanism induced by phenolic resin/PEO and floc properties. AIChE J. 2005, 51 (3), 1022.

40. Negro, C.; Sanchez, L.M., Fuente, E.; Blanco, A; Tijero, J. Polyacrylamide induced flocculation of a cement suspension. Chem. Eng. Sci. 2006, 61 (8), 2522.

41. Dunham, A.J.; Sherman, L.M.; Alfano, J.C. Effect of dissolved and colloidal substances on drainage properties of mechanical pulp suspensions. J. Pulp Pap. Sci. 2002, 28 (9), 298.

42. Sundberg, A.; Ekman, R.; Holmbom, B.; Gronfors, H. Interactions of cationic polymers with components in thermomechanical pulp suspensions. Pap. Puu-Pap. Timb. 1994, 76 (9), 593.

43. Burnet, A.; Marlin, N.; Carre, B.; Fabry, B.; Ayala, C.; Chirat, C. Influence of paper grades and bleaching chemicals on DIP brightness and effluent quality. Prog. Pap. Recycl. 2007, 17 (1), 5.

44. Wong, S.S.; Teng, T.T.; Ahmad, A.L.; Zuhairi, A.; Najafpour, G. Treatment of pulp and paper mill wastewater by polyacrylamide (PAM) in polymer induced flocculation. J. Haz. Mats. 2006, 135 (1-3), 378.

45. Ahmad, A.L.; Wong, S.S.; Teng, T.T.; Zuhairi, A. Improvement of alum and PACl coagulation by polyacrylamides (PAMs) for the treatment of pulp and paper mill wastewater. Chem. Eng. J. 2007, doi: 10.1016/j.cej.2007.03.088.

46. Nylund, J. Cationic Polyelectrolytes on Cellulosic Fibres. Thesis dissertation. 1997. Åbo Akademi University (Finland).

47. Nurmi, M.; Wallin, S.; Eklund, D. Interactions between cationic polyacrylamide and TMP. Wochenbl. Papierfabr. 2003, 131 (11-12), 678.

48. Wagberg, L.; Nordqvist, T. Detection of polymer induced flocculation of cellulosic fibres by image analysis. Nord. Pulp Pap. Res. J. 1999, 14(3), 247. 
49. Nurmi, M. Studies on the interactions between thermomechanical pulp and cationic polyacrylamide. Thesis dissertation. 2003. Åbo Akademi University (Finland).

50. Nurmi, M.; Eklund, D. Effect of cationic polyacrylamide on colloidal wood resin. Pap. PuuPap. Timb. 2000, 82 (4), 331.

51. Wagberg, L.; Odberg, L. The action of polyelectrolytes used for the fixation of dissolved and colloidal substances. Nord. Pulp Pap. Res. J. 1991, 6 (3), 127. 
Table 1. Characteristics of the flocculants.

\begin{tabular}{|c|c|c|}
\hline Polymer & $\begin{array}{c}\text { Molecular } \\
\text { weight (Da) }\end{array}$ & $\begin{array}{c}\text { Charge density } \\
\text { (meq/g) }\end{array}$ \\
\hline C1 & \multirow{5}{*}{$9 \cdot 10^{6}$} & 1.0 \\
\hline C2 & & 1.5 \\
\hline C3 & & 2.5 \\
\hline C4 & & 3.0 \\
\hline $\mathrm{C} 5$ & & 3.5 \\
\hline A1 & \multirow[b]{3}{*}{ (Very high) } & 0.75 \\
\hline A2 & & 0.925 \\
\hline A3 & & 1.5 \\
\hline
\end{tabular}


Table 2. Characterization of the water sample from the inlet of the DAF unit.

\begin{tabular}{|l|l|}
\hline $\mathrm{pH}$ & 7.8 \\
\hline Conductivity $\left(25^{\circ} \mathrm{C}\right)$ & $1662 \mu \mathrm{S} / \mathrm{cm}$ \\
\hline Turbidity & $1200 \mathrm{NTU}$ \\
\hline Cationic demand & $0.83 \mathrm{meq} / \mathrm{L}$ \\
\hline COD & $1461 \mathrm{ppm}$ \\
\hline
\end{tabular}


Table 3. Correlation of DAF efficiency with cationic demand and FBRM statistics. Single systems. Note: C1 is not included in these fits.

\begin{tabular}{|l|l|l|}
\hline \multirow{2}{*}{} & \multicolumn{2}{|c|}{$\mathbf{R}^{2}$} \\
\cline { 2 - 3 } & Turbidity & COD \\
\hline Cationic demand & 0.773 & 0.815 \\
\hline Number of counts/s $(10-100 \mu \mathrm{m})$ & 0.946 & 0.868 \\
\hline Total number of counts $(\# / s)$ & 0.733 & 0.844 \\
\hline Mean chord size $(1-1000 \mu \mathrm{m})$ & 0.900 & 0.756 \\
\hline
\end{tabular}


Table 4. Correlation of DAF efficiency with cationic demand and FBRM statistics. Dual systems.

\begin{tabular}{|l|l|l|}
\hline & \multicolumn{2}{|c|}{$\mathbf{R}^{2}$} \\
\hline & Turbidity & COD \\
\hline Cationic demand & 0.001 & 0.003 \\
\hline Number of counts/s $(10-100 \mu \mathrm{m})$ & 0.891 & 0.840 \\
\hline Total number of counts $(\# / s)$ & 0.888 & 0.835 \\
\hline Mean chord size $(1-1000 \mu \mathrm{m})$ & 0.617 & 0.664 \\
\hline
\end{tabular}




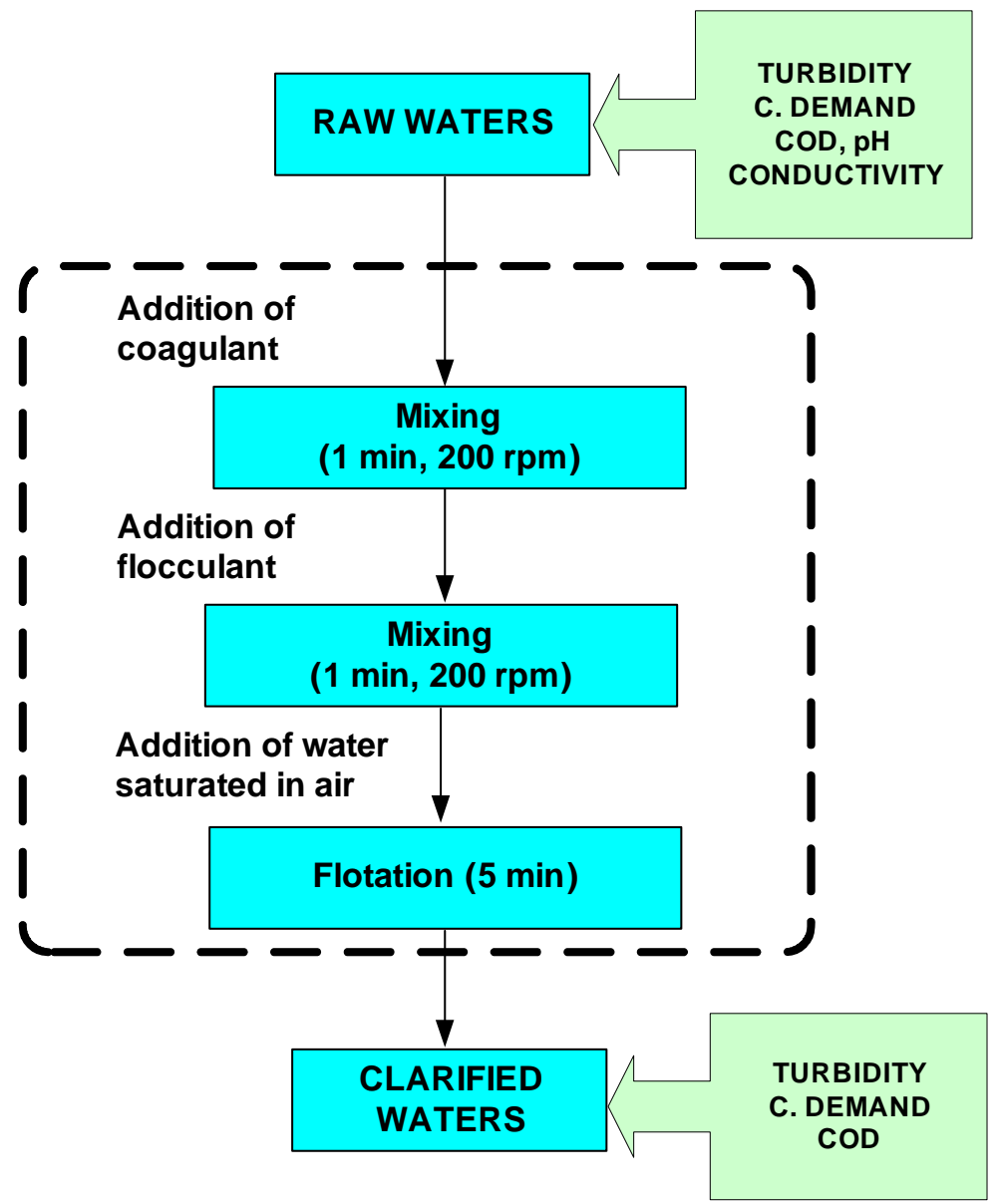

Figure 1. Experimental protocol for the determination of chemical efficiency in a DAF unit. 


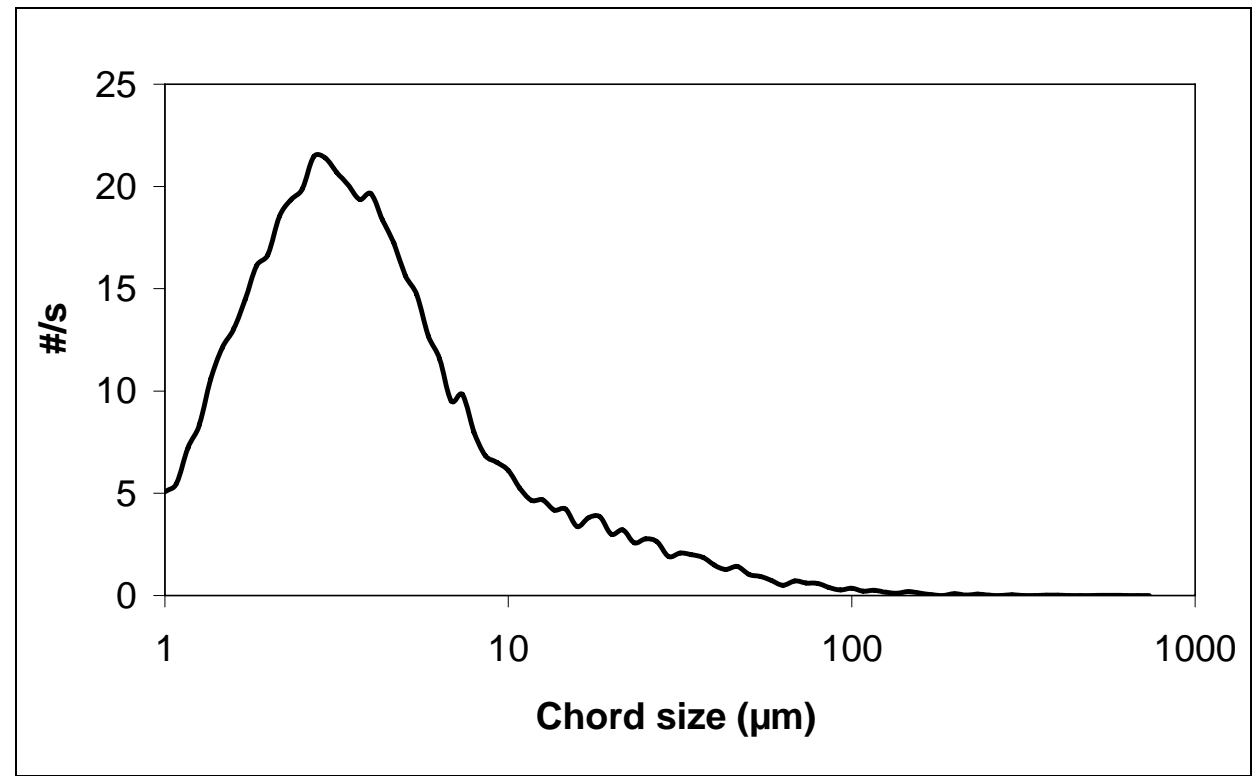

Figure 2. Chord size distribution of the sample from the inlet of the DAF unit. 


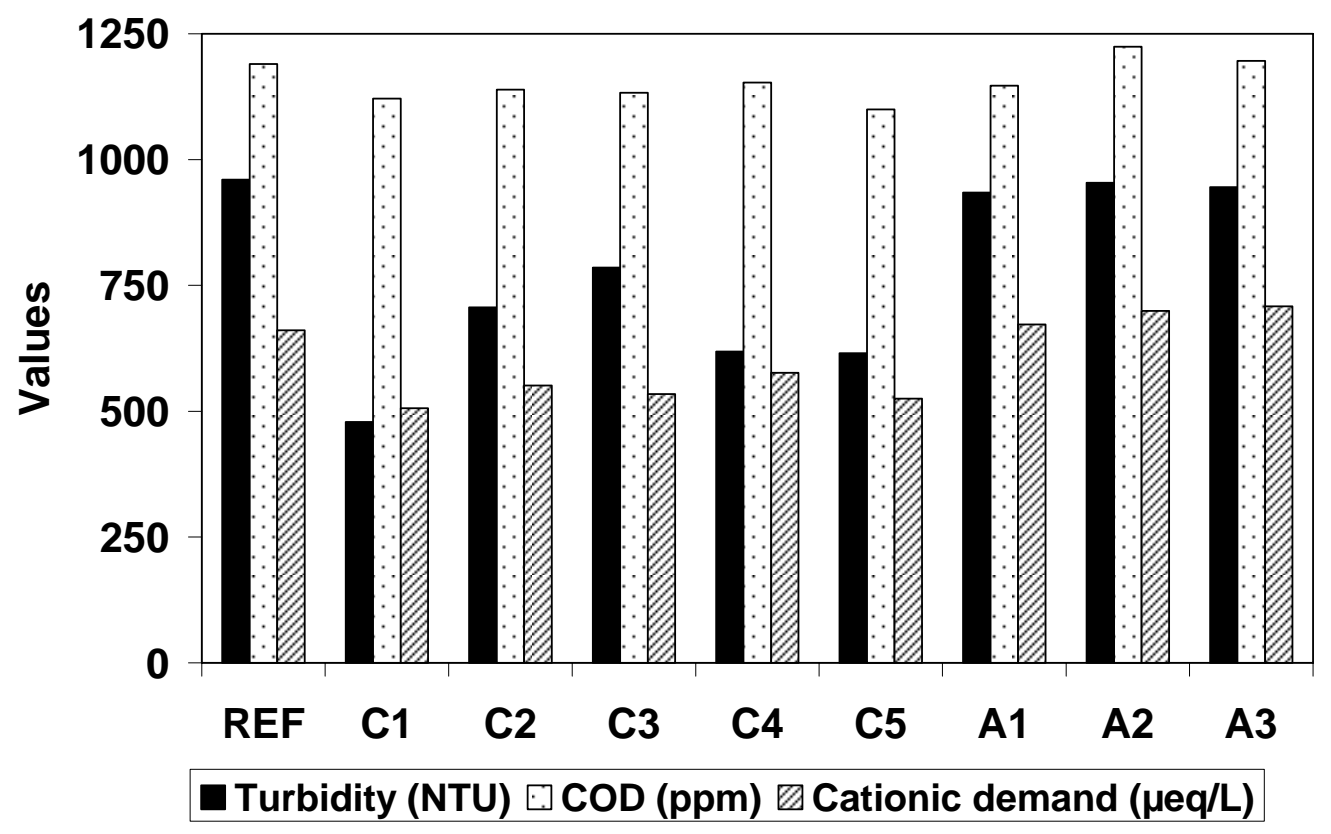

Figure 3. Turbidity, COD and cationic demand of clarified waters in DAF tests (single systems). 

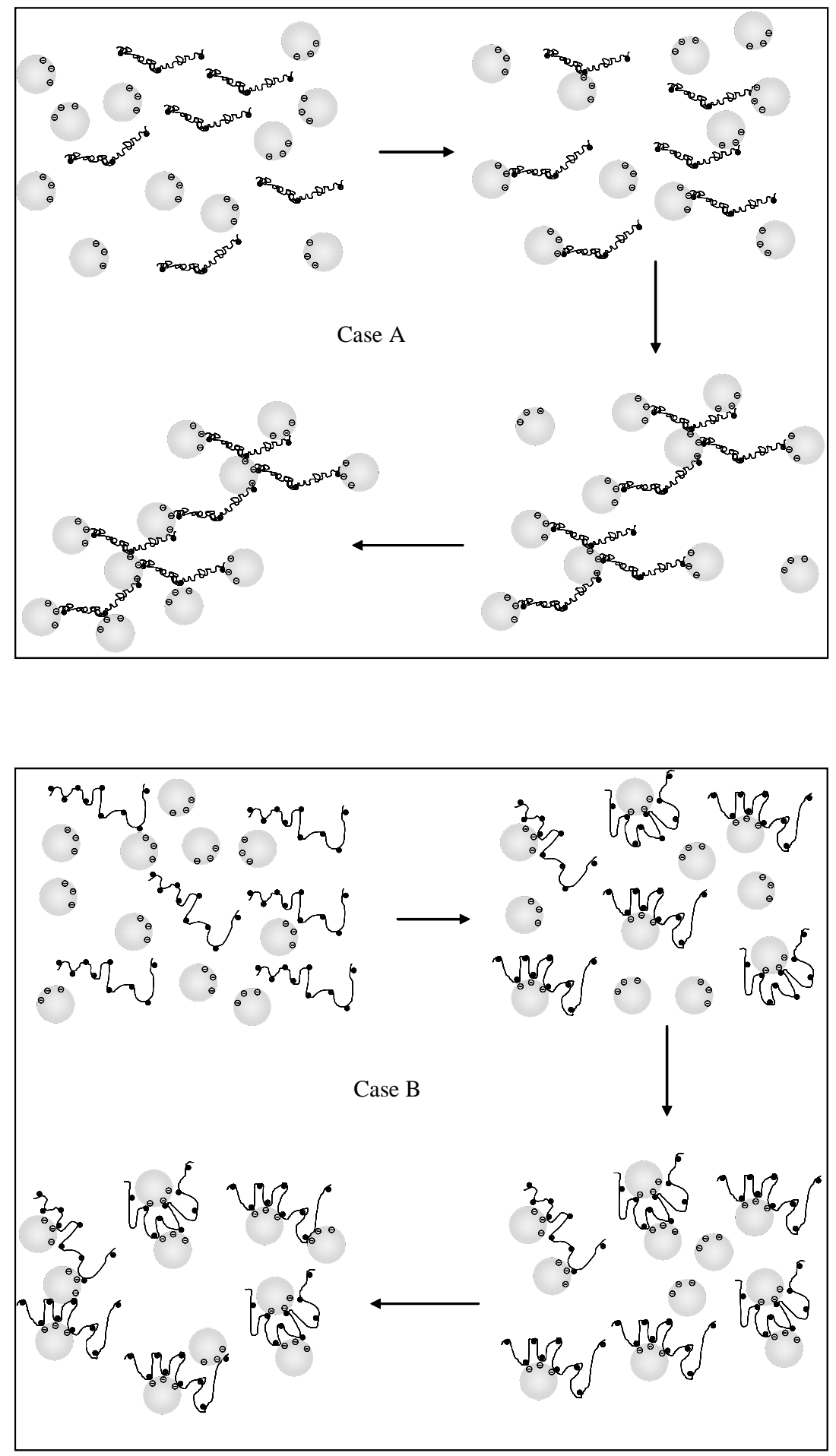

Figure 4. Proposed scheme of the flocculation mechanism. Case A: C1. Case B: a high charged C-PAM. 


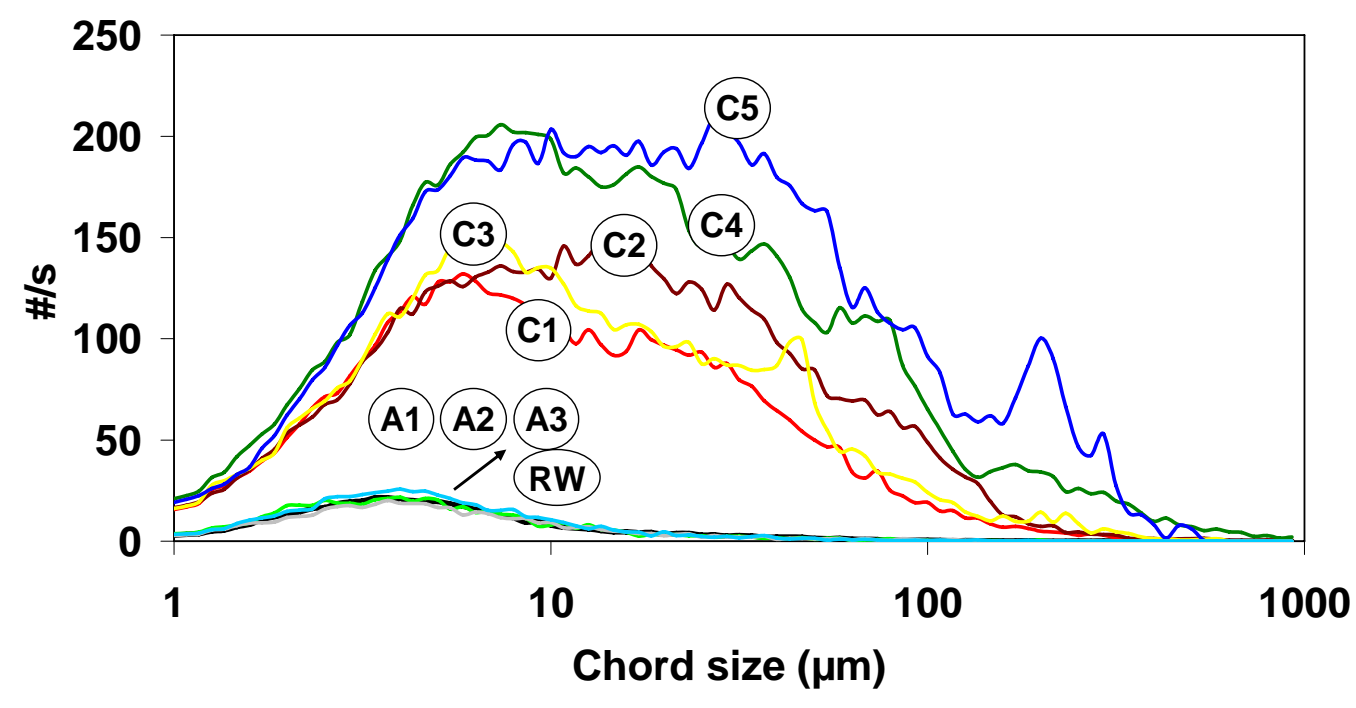

$-\mathrm{RW}-\mathrm{C} 1-\mathrm{C} 2-\mathrm{C} 3-\mathrm{C} 4-\mathrm{C} 5-\mathrm{A} 1-\mathrm{A} 2-\mathrm{A} 3$

Figure 5. Chord size distribution of the waters after $10 \mathrm{~s}$ of the flocculant addition (single systems). 


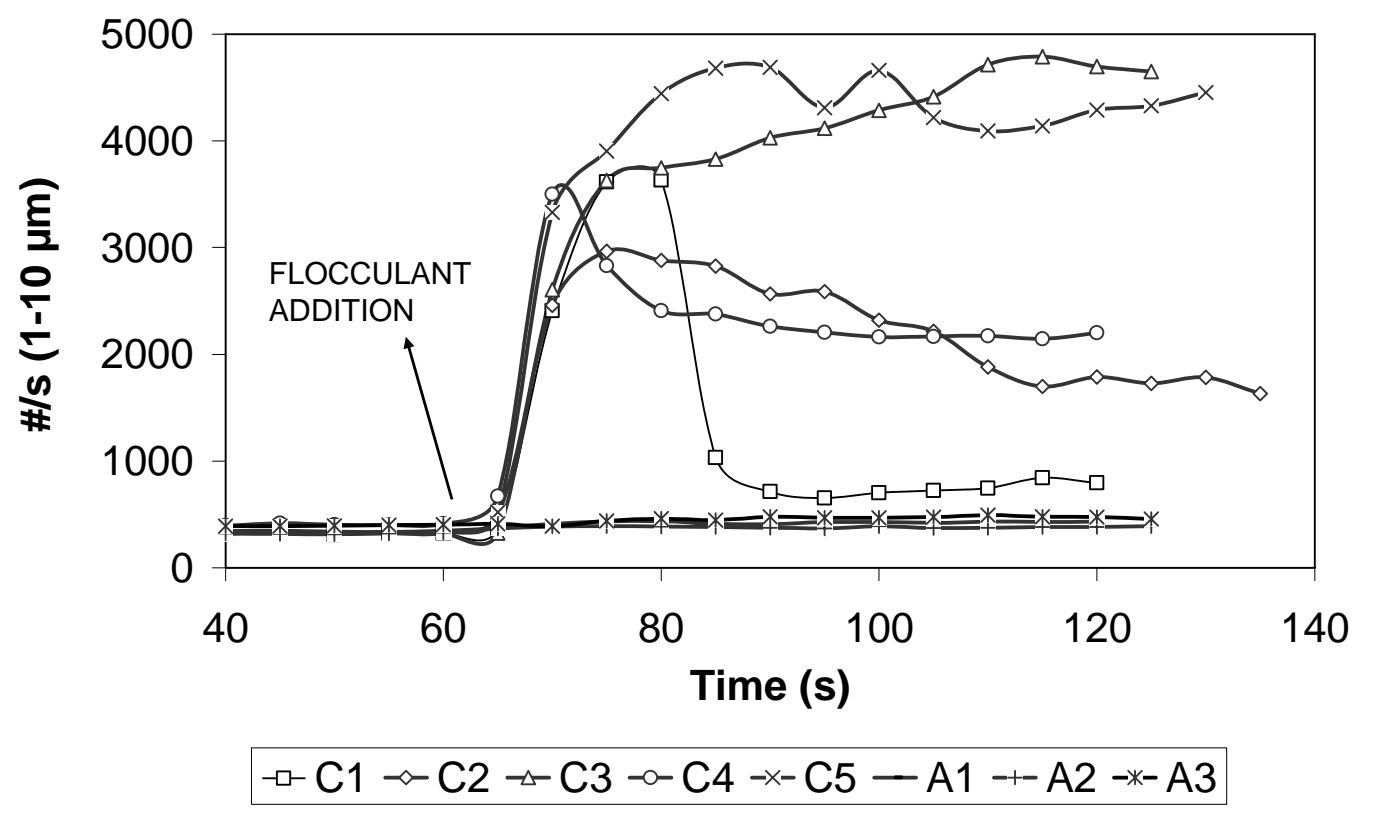

Figure 6. Evolution of the number of chords/s in the range 1-10 $\mu \mathrm{m}$ along the flocculation process (single systems). 


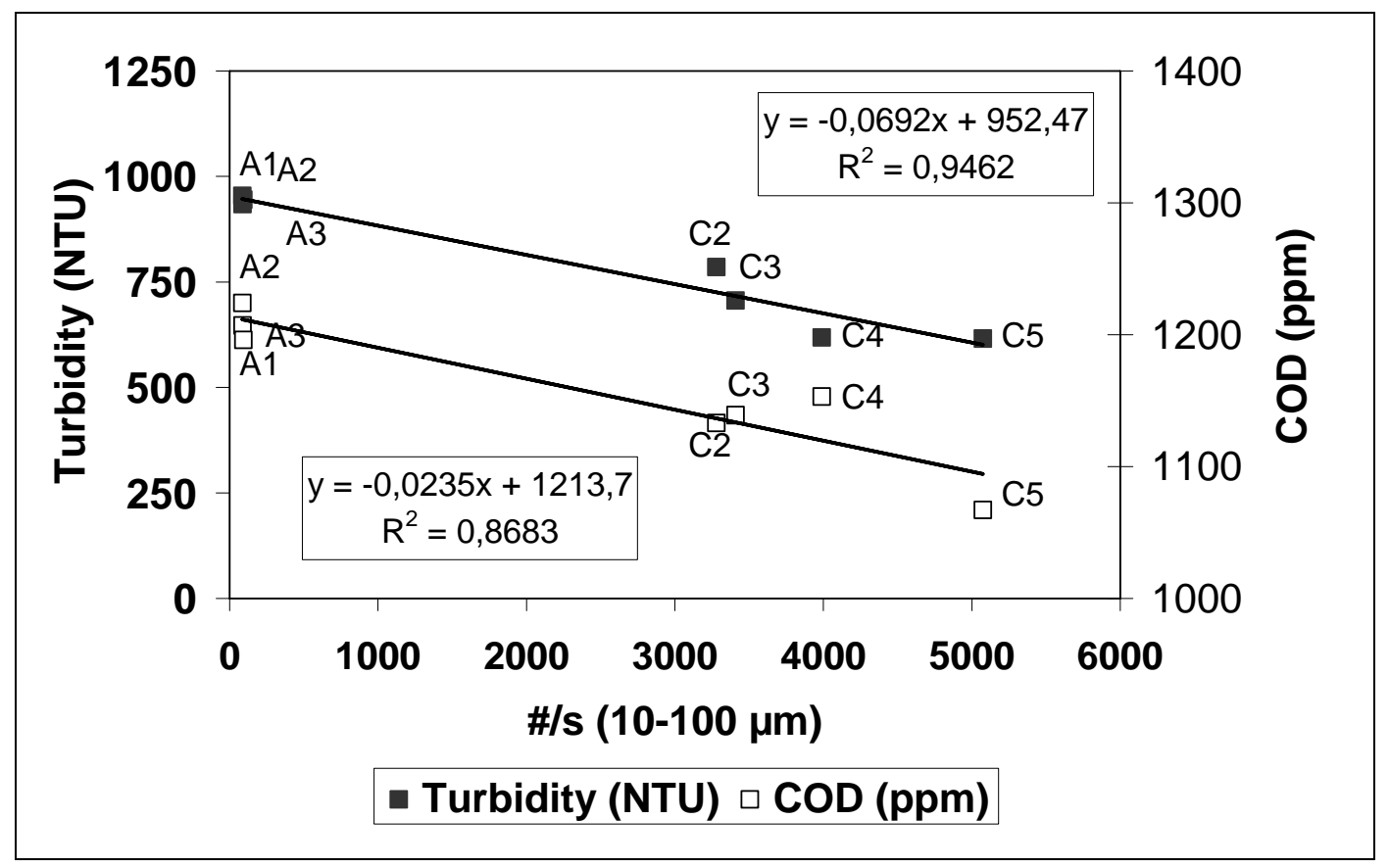

Figure 7. Relationship between turbidity and COD of the clarified waters by DAF and the number of counts/s between 10-100 $\mu$ m, measured by FBRM, at the moment of maximum flocculation. 


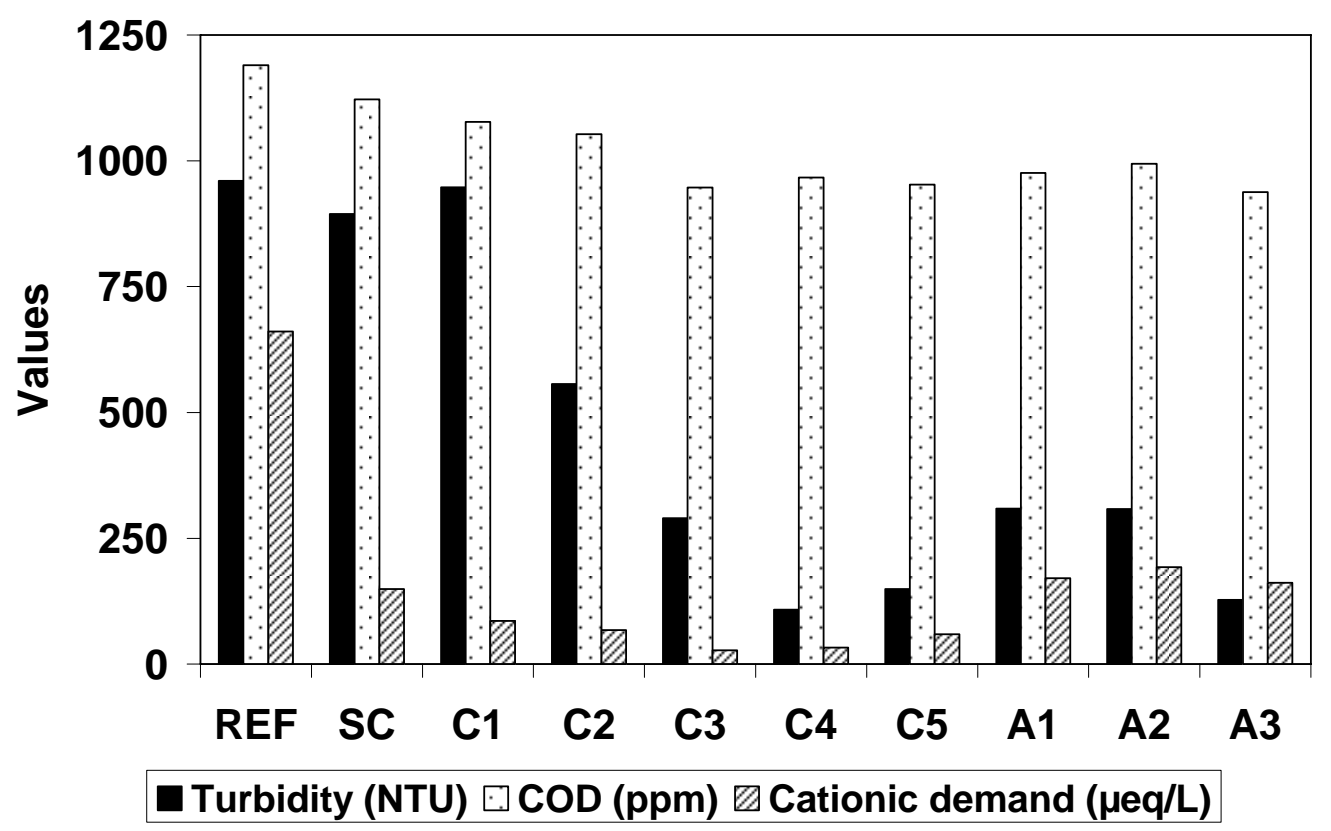

Figure 8. Turbidity, COD and cationic demand of clarified waters in DAF tests (coagulant alone and dual systems). 


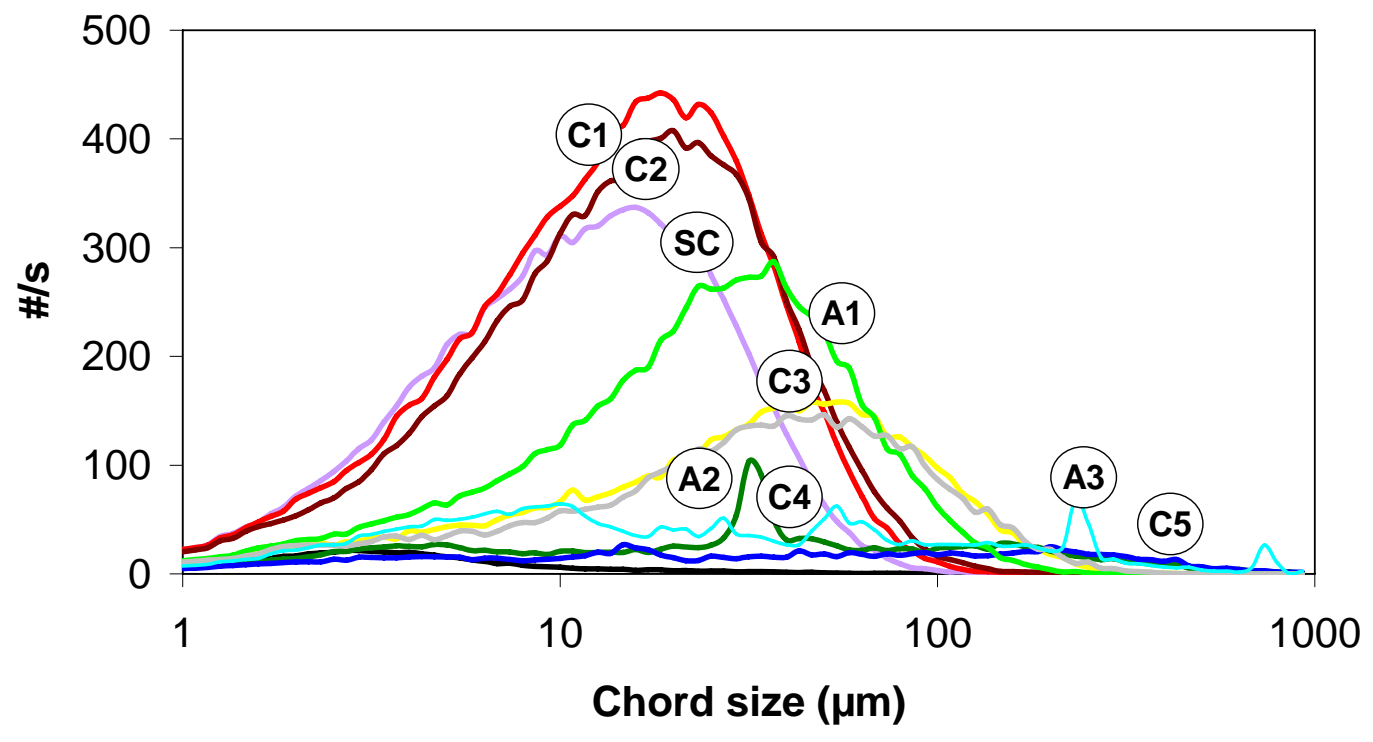

$-\mathrm{RW}-\mathrm{SC}-\mathrm{C} 1-\mathrm{C} 2-\mathrm{C} 3-\mathrm{C} 4-\mathrm{C} 5-\mathrm{A} 1-\mathrm{A} 2-\mathrm{A} 3$

Figure 9. Chord size distribution of the waters after $10 \mathrm{~s}$ of the flocculant addition (dual systems). 


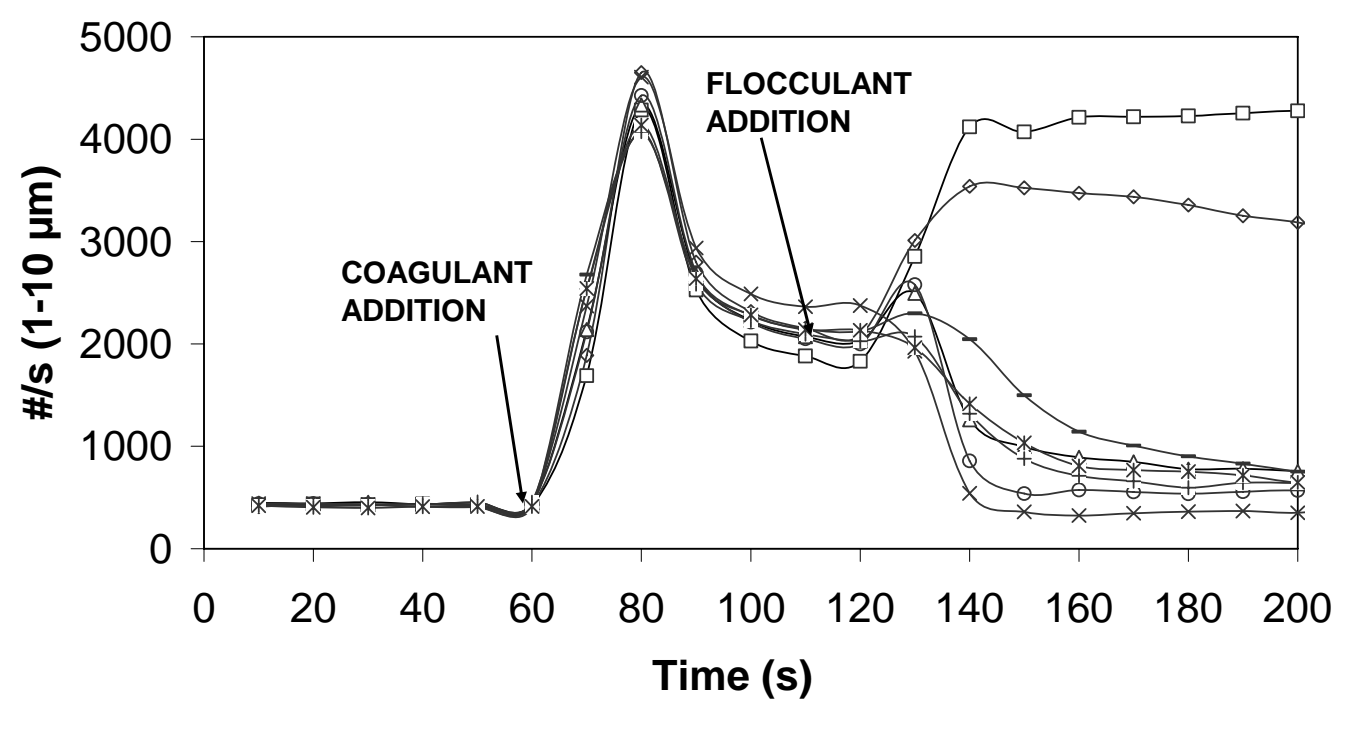

$\rightarrow \mathrm{C} 1 \leftrightarrow \mathrm{C} 2 \triangleleft \mathrm{C} 3 \rightarrow \mathrm{C} 4 * \mathrm{C} 5-\mathrm{A} 1+\mathrm{A} 2-\mathrm{A} 3$

Figure 10. Evolution of the number of chords/s in the range $1-10 \mu \mathrm{m}$ along the flocculation process (dual systems). 


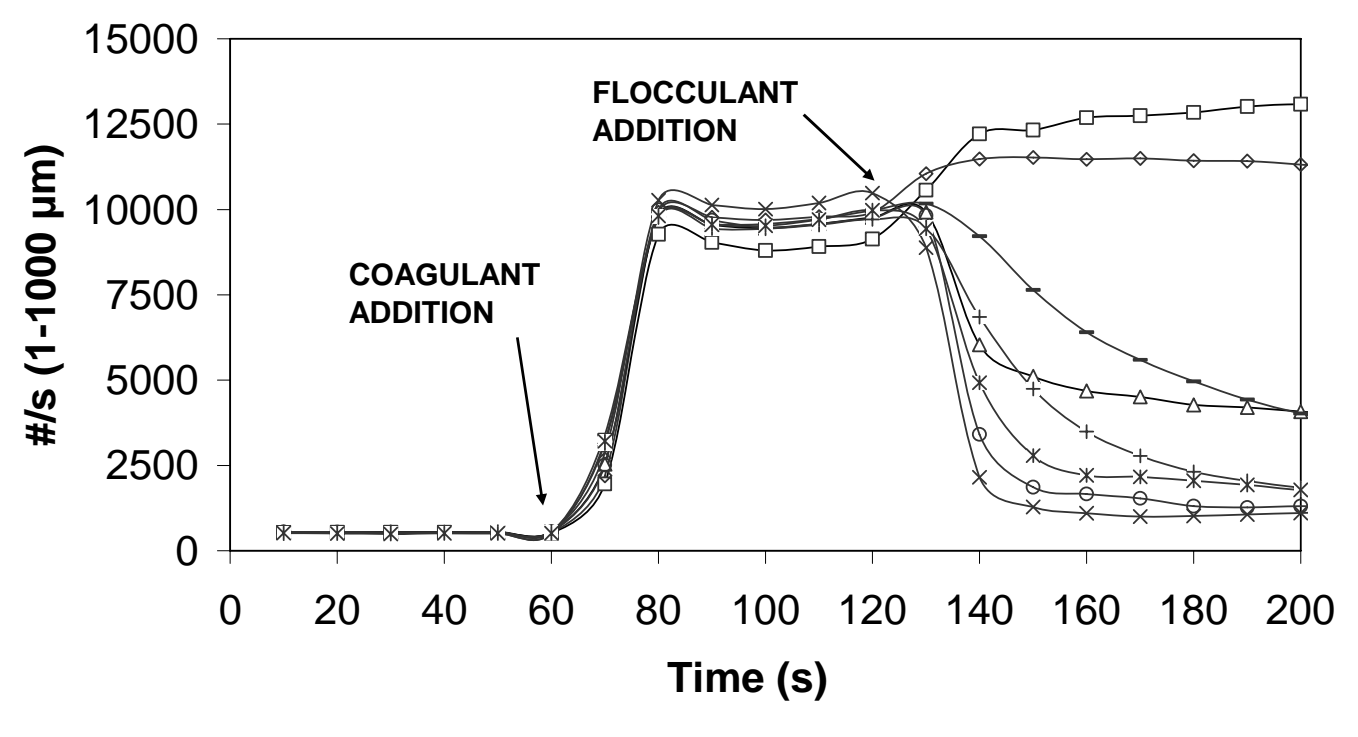

$\rightarrow-\mathrm{C} 1 \leftrightarrow \mathrm{C} 2 \triangleleft \mathrm{C} 3 \rightarrow \mathrm{C} 4 * \mathrm{C} 5-\mathrm{A} 1+\mathrm{A} 2-*-\mathrm{A} 3$

Figure 11. Evolution of the total number of chord/s (1-1000 $\mu \mathrm{m})$ along the flocculation process (dual systems). 


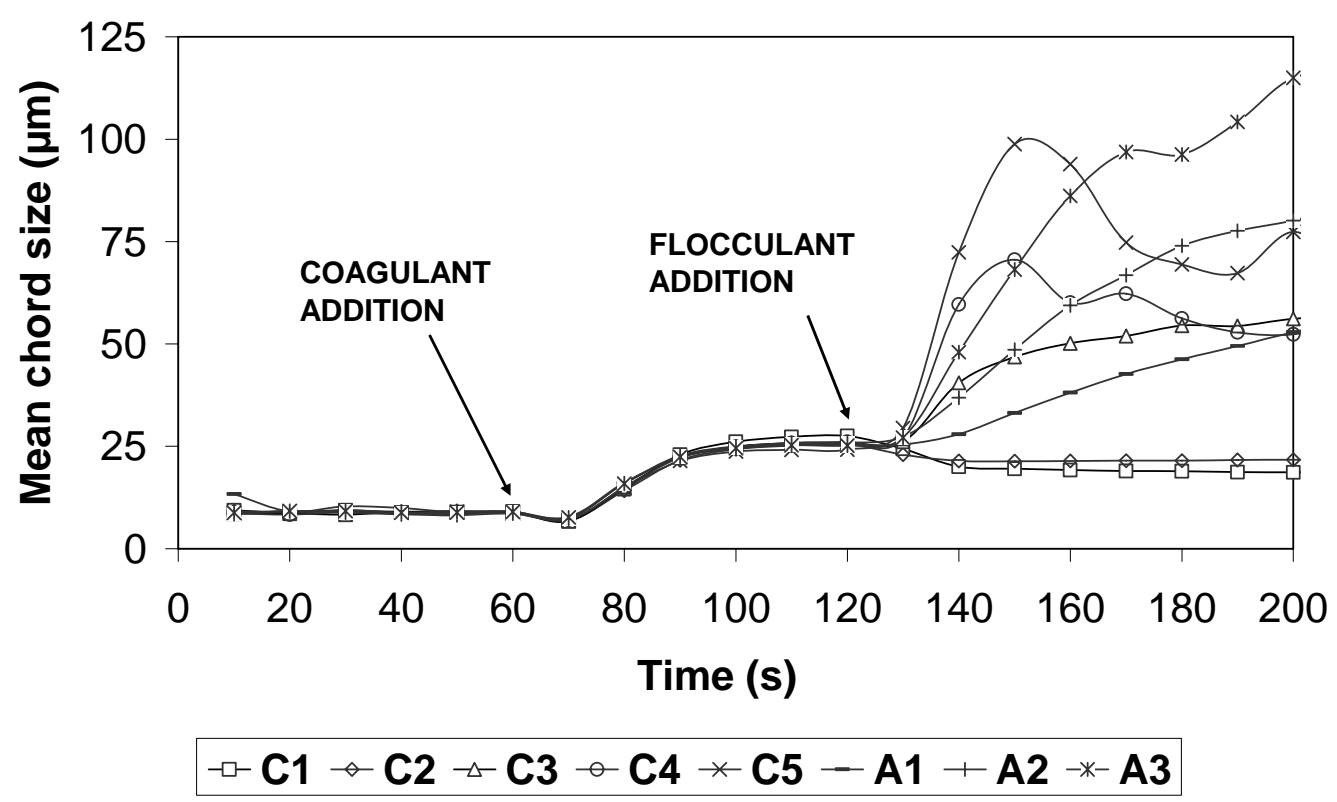

Figure 12. Evolution of the mean chord size $(1-1000 \mu \mathrm{m})$ along the flocculation process (dual systems). 


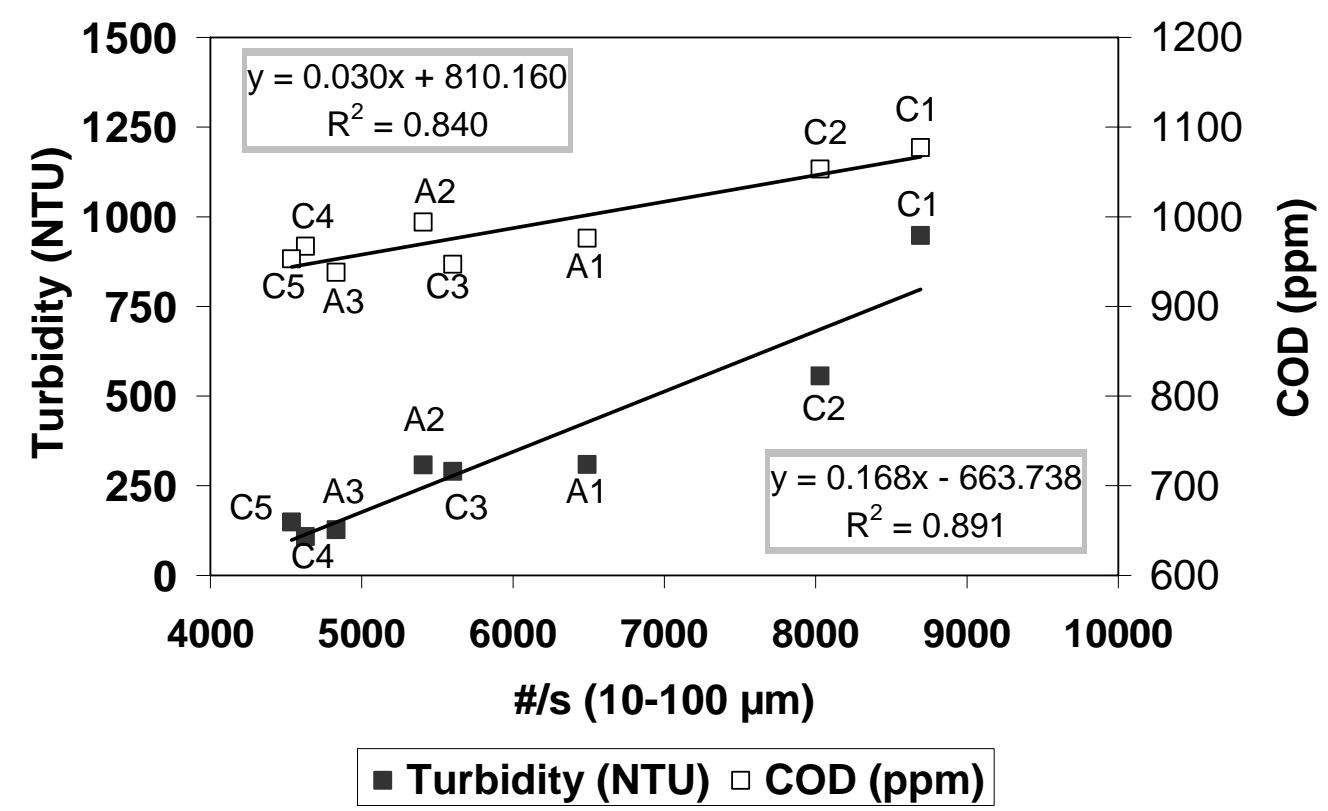

Figure 13. Relation between turbidity and COD of the clarified waters by DAF and the number of counts/s between 10-100 $\mu$ m, measured by FBRM, at the moment of maximum flocculation. 


\section{FIGURE LEGENDS}

Figure 1. Experimental protocol for the determination of chemical efficiency in a DAF unit.

Figure 2. Chord size distribution of the sample from the inlet of the DAF unit.

Figure 3. Turbidity, COD and cationic demand of clarified waters in DAF tests (single systems).

Figure 4. Proposed scheme of the flocculation mechanism. Case A: C1. Case B: a high charged C-PAM.

Figure 5. Chord size distribution of the waters after $10 \mathrm{~s}$ of the flocculant addition (single systems).

Figure 6. Evolution of the number of chords/s in the range 1-10 $\mu \mathrm{m}$ along the flocculation process (single systems).

Figure 7. Relationship between turbidity and COD of the clarified waters by DAF and the number of counts/s between 10-100 $\mu$ m, measured by FBRM, at the moment of maximum flocculation.

Figure 8. Turbidity, COD and cationic demand of clarified waters in DAF tests (coagulant alone and dual systems).

Figure 9. Chord size distribution of the waters after $10 \mathrm{~s}$ of the flocculant addition (dual systems).

Figure 10. Evolution of the number of chords/s in the range $1-10 \mu \mathrm{m}$ along the flocculation process (dual systems).

Figure 11. Evolution of the total number of chord/s (1-1000 $\mu \mathrm{m})$ along the flocculation process (dual systems).

Figure 12. Evolution of the mean chord size $(1-1000 \mu \mathrm{m})$ along the flocculation process (dual systems). 
Figure 13. Relation between turbidity and COD of the clarified waters by DAF and the number of counts/s between 10-100 $\mu \mathrm{m}$, measured by FBRM, at the moment of maximum flocculation. 